\title{
Epidemiology and Treatment Outcome of Mucormycosis in Khuzestan, Southwest of Iran
}

\author{
Roohangiz Nashibi, ${ }^{1,2}$ Sara Afzalzadeh, ${ }^{1,2}$ Mohammad Javad Mohammadi, ${ }^{3,4,5}$ Ahmad Reza Yari, ${ }^{6}$ and \\ Farid Yousefi, ${ }^{1,2}$ \\ ${ }^{1}$ Health Research Institute, Infectious and Tropical Diseases Research Center, Ahvaz Jundishapur University of Medical Sciences, Ahvaz, Iran \\ ${ }^{2}$ Department of Infectious and Tropical Diseases, Razi Hospital, Faculty of Medicine, Ahvaz Jundishapur University of Medical Sciences, Ahvaz, Iran \\ ${ }^{3}$ Abadan School of Medical Sciences, Abadan, Iran \\ ${ }^{4}$ Razi Teaching Hospital, Clinical Research Development Center, Ahvaz Jundishapur University of Medical Sciences, Ahvaz, Iran \\ ${ }^{5}$ Student Research Committee, Department of Environmental Health Engineering, School of Public Health and Environmental Technologies Research Center, Ahvaz \\ Jundishapur University of Medical Sciences, Ahvaz, Iran \\ ${ }^{6}$ Research Center for Environmental Pollutants, Qom University of Medical Sciences, Qom, Iran \\ "Corresponding author: Farid Yousefi, Department of Infectious and Tropical Diseases, Razi Hospital, Faculty of Medicine, Ahvaz Jundishapur University of Medical Sciences, \\ Ahvaz, Iran. Tel: +98-9355439707, Fax: +98-6133336513, E-mail: drfayo@gmail.com
}

Received 2016 February 18; Revised 2016 September 03; Accepted 2016 September 28.

\begin{abstract}
Background: Mucormycosis is an uncommon life-threatening fungal infection. The major risk factors of this infection include uncontrolled diabetes mellitus, prolonged steroid therapy, persistent neutropenia, hematological malignancies, autoimmune disorders, trauma, burns and surgical wounds.

Objectives: The current study aimed to determine the epidemiology and treatment outcome of mucormycosis in Khuzestan province, southwest of Iran.

Methods: This cross-sectional study was performed during a period of 10 years from April 2004 to March 2014 at Razi hospital in Ahvaz, southwest of Iran, during years 2004 to 2014. Demographic data, laboratory data, clinical features, antifungal treatment, the need for surgical debridement and the outcome were collected. Data were summarized using descriptive statistical methods and analyzed by SPSS version 15 software.

Results: The study included 20 patients with a biopsy-proven diagnosis of mucormycosis. Regarding the findings, the mean age was $51.4 \pm 9.7$ years. Eighty-five percent of patients had uncontrolled diabetes mellitus. Findings showed that all the cases received amphotericin B, but surgical debridement was performed on 10 patients (50\%). Most prevalent season of mucormycosis was winter (40\%).

Conclusions: Prognosis of patients that underwent surgery and medical therapy was significantly better than medical therapy alone (90\% vs. $50 \%$ patient's survival).
\end{abstract}

Keywords: Mucormycosis, Epidemiology, Outcome

\section{Background}

Mucormycosis is an uncommon life-threatening infection caused by fungi of class Zygomycetes, other Mucorales, and are ubiquitous fungi in the environment that are commonly found in decaying organic substrates, including bread, fruits, vegetables, soil, compost piles and animal excreta (1-4). The principle risk factors associated with mucormycosis include uncontrolled diabetes and diabetic ketoacidosis, prolonged steroid therapy, persistent neutropenia, deferoxamine therapy, hematological malignancies, illicit use of intravenous drugs, autoimmune disorders, prophylaxis with voriconazole or echinocandins, and cutaneous or mucous membrane barrier due to trauma, burns and surgical wounds. However, it has also been described in patients with no underlying disease (5-10). This infection is more common among people with suppressed immune systems, but it can rarely occur in people, who are otherwise healthy (11). The primary mode of acquisition of mucormycosis is inhalation of spores from environmental sources (12). Other modes of acquisition include the cutaneous route with traumatic disruption of skin barriers, burns or direct injection or catheters (13). Gastrointestinal mucormycosis, although less common, has been reported in immunosuppressed patients (14). The site of infection varies, and can occur in the lungs, the skin and soft tissue, the rhino-orbito-cerebral region and the gastrointestinal tract (15). A classic feature of mucormycosis is tissue necrosis, as a result of vascular invasion and subsequent thrombosis (16). The treatment strategy involves timely diagnosis and aggressive surgical debridement combined with high dose amphotericin B and reversal of underlying predisposing factors whenever possible $(15,17)$. The site of infection 
and underlying host factors are the key prognostic determinants of mucormycosis outcome. The mortality rate of patients, who received systemic antifungal therapy alone was $55 \%$ compared with $27 \%$ in patients, who received antifungal therapy plus surgical management (14). Knowing these features may increase the chance of an early diagnosis, which in turn may prevent aggressive tissue invasion, reduce the need for extensive surgical debridement and improve survival.

\section{Objectives}

The current study aimed to assess the demographic characteristics of mucormycosis, underlying conditions, the most prevalent season of involvement, and outcome of patients from Razi hospital in Ahvaz, southwest of Iran, during years 2004 and 2014.

\section{Methods}

\subsection{Method}

This cross-sectional study was performed at Razi teaching hospital, Ahvaz (principle referral center for infectious diseases in Khuzestan province). Location of the study was in the south west of Ahvaz city, Razi hospital, with approximately 220 beds, which is located between $48^{\circ}$ and $49^{\circ} 29^{\prime}$ east of the Greenwich meridian, $31^{\circ}$ and $45^{\prime}$ minutes north of the equator $(8,18,19)$. Data were collected during a period of 10 years from April 2004 to March 2014, including demographic information, underlying conditions, concomitant immunosuppressive medications, laboratory data, radiologic findings, clinical features, antifungal treatment, the need for surgical debridement and outcome. The patients included in the study had a proven diagnosis of mucormycosis by biopsy from suspected lesions and demonstration of broad, ribbon-like, wide-angled branching, and non-septate hyphae even in the absence of positive culture and tissue invasion by fungal hyphae. Patients with human immunodeficiency virus (HIV) infection were excluded from the study. All the patients were treated with deoxycholate amphotericin B, at a dose of $1 \mathrm{mg}$ per kilogram body weight daily, that was administered over four to six hours after infusion of a test dose of $1 \mathrm{mg}$ of the drug in $100 \mathrm{~mL}$ of normal saline.

\subsection{Statistical Analysis}

Data were analyzed using the SPSS version 15 software. $P$ values were considered significant when $\mathrm{P}<0.05$. Means were compared using Fisher's exact test.

\section{Results}

Twenty patients with biopsy-proven mucormycosis participated in the study. Thirteen patients (65\%) were males and seven (35\%) were females. The mean age was 51.4 \pm 9.7 years ( 20 - 68 years) (Table 1 ).

The most common underlying condition in these patients was uncontrolled diabetes mellitus that was reported in 17 cases (85\%). Other conditions, each found in one case included trauma (5\%), using glucocorticoids (5\%) and dental extraction (5\%). The most common site of involvement was the rhinocerebral region, occurring in six cases (30\%). All patients received amphotericin B but surgical debridement was performed in 10 patients (50\%) with complete excision of the infected area. The most common involved sinus was maxillary in nine cases (45\%), and the most common affected cranial nerve was the third, occurring in 13 cases (65\%). Also, as demonstrated in Figure 1, our study showed that the most prevalent season of mucormycosis was winter with eight cases (40\%).

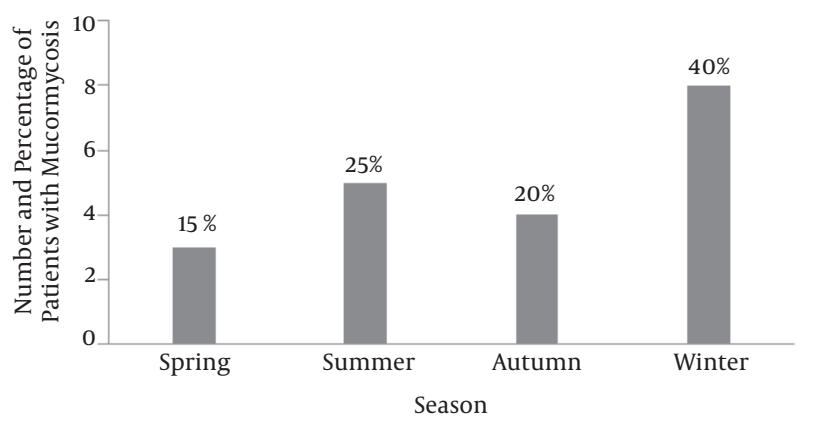

Figure 1. Distribution of Season of Mucormycosis in Khuzestan

\subsection{Outcome of Patients}

Overall, 15 out of 20 patients (75\%) were cured and five patients (25\%) passed away, and one patient (5\%) was complicated by blindness. Neither of the five patients who passed away underwent surgical debridement, while surgery was performed for ten out of 15 patients, who survived. Fifty percent of patients treated with amphotericin B alone, survived. We performed Fisher's exact test for evaluation of the relationship between surgery and reduced mortality and found a significant association $(\mathrm{P}=0.033)$.

\section{Discussion}

Mucormycosis is a rare life-threatening infection, which may lead to high mortality and this infection 
Table 1. Demographic Characteristics of Patients With Mucormycosis

\begin{tabular}{|c|c|}
\hline Characterization & \\
\hline \multicolumn{2}{|l|}{ Demographic data, No. (\%) } \\
\hline Patients & 20 \\
\hline \multicolumn{2}{|l|}{ Age } \\
\hline Year & $51.4 \pm 9.7$ \\
\hline Range & $20-68$ \\
\hline \multicolumn{2}{|l|}{ Gender } \\
\hline Male & 13 \\
\hline Female & 7 \\
\hline \multicolumn{2}{|l|}{ Underlying conditions, No. (\%) } \\
\hline Uncontrolled diabetes mellitus & $17(85)$ \\
\hline Trauma & $1(5)$ \\
\hline Using glucocorticoids & $1(5)$ \\
\hline Dental extraction & $1(5)$ \\
\hline \multicolumn{2}{|l|}{ Site of involvement, No. (\%) } \\
\hline Rhino-cerebral & $6(30)$ \\
\hline Sino-orbital-cerebral & $5(25)$ \\
\hline Sinus & $5(25)$ \\
\hline Orbital & $3(15)$ \\
\hline Sino-orbital & $1(5)$ \\
\hline Necrosis of palate & $10(50)$ \\
\hline \multicolumn{2}{|l|}{ Cranial nerve involvement, No. (\%) } \\
\hline Optic nerve & $4(20)$ \\
\hline $3^{\text {rd }}$ nerve & $13(65)$ \\
\hline $4^{\text {th }}$ nerve & $11(55)$ \\
\hline $5^{\text {th }}$ nerve & $6(30)$ \\
\hline $6^{\text {th }}$ nerve & $11(55)$ \\
\hline $7^{\text {th }}$ nerve & $6(30)$ \\
\hline
\end{tabular}

mostly afflicts immune-compromised or severely hyperglycemic patients (14). In this study, mucormycosis was more prevalent in males than in females (65\% vs. $35 \%$ ). This finding was similar to the results of a large review by Roden et al. in 2005, which reported that male gender constituted 65\% of the cases (16). Also Mohinisingh in 2015 (20) and Sachdeva in India (21) reported results similar to our findings. In our study, the median age of patients was 51 years that is slightly lower than the study performed by Saegeman et al. in Belgium with a mean age of 60 years (22). In this study, uncontrolled diabetes mellitus was the most common risk factor for mucormycosis (85\%). This finding was in accordance with the results obtained by Mohinisingh in 2015 (85.7\%) (20), Khor et al. in Taiwan
(95\%) (23), and Barati et al. in Tehran (60\%) (24). However, in some studies, hematologic and non-hematologic malignancies were reported as the most common underlying predisposing factor $(10,25)$. In general, the mechanism responsible for the increased susceptibility to mucormycosis is immunodeficiency. In mucormycosis, the infection mostly develops after inhalation of fungal spores into the paranasal sinuses and then may rapidly progress to adjacent tissues and spread inferiorly to the palate, posteriorly to the sphenoid sinus, laterally into the cavernous sinus to involve the orbits, or cranially to invade the brain (26). In our patients, the most common type of mucormycosis was rhino cerebral, the reason of which was not clear. Studies carried out by Hong et al., Sarvestani et al., Petrikkos et 
al. and Komur et al. also showed similar results $(10,14$, $26,27)$. In contrast, studies conducted by Saegeman et al. in Belgium and pagano et al. in Italy, demonstrated that pulmonary mucormycosis was the most common type of infection, probably because in both studies most of the patients had hematological malignancies $(22,28)$. Our study displayed that winter was the most common season for the occurrence of mucormycosis; similarly, the study performed in Athens by Bartzokas, showed that during autumn and winter, the number of mucormycosis was twice as high as in spring and summer (29). Since the weather in our region, Khuzestan, is somewhat similar to that of autumn in other countries in the Middle East, the minor differences in the most frequent time of the year could be justified.

Also, a previous study conducted by EI-Herte et al. suggested that mucormycosis has a seasonal variation, and a positive correlation with humidity and a negative correlation with temperature (30). Prognosis of patients that underwent surgery in addition to medical therapy was significantly better than those with medical therapy alone (90\% vs. 50\% survival rate; $\mathrm{P}=0.033$ ). pagano et al. and Chakrabarti et al. also obtained results similar to our findings $(28,31)$. The limitation of this study was its small sample size because of the rarity of this invasive fungal infection, so we propose more studies with larger sample sizes to be performed in the future.

\subsection{Conclusion}

There were some limitations in the current study such as small sample size. Based on our findings, it seems that the outcome of patients managed with a combination of surgery and medical therapy could be better than patients receiving medical therapy alone. Also, seasonal variations appear to affect the prevalence of the disease.

\section{Acknowledgments}

The authors would like to thank the student research committee, Ahvaz Jundishapur University of Medical Sciences for providing financial supported by grant 94 s160.

\section{Footnotes}

Authors' Contribution: Study concept, design, and critical revision of the manuscript for important intellectual content, Farid Youesfi, Roohangiz Nashibi, Mohammad Javad Mohammadi and Sara Afzalzadeh. Drafting of the manuscript, provision advice and performing of the experiments, Sara Afzalzadeh
Conflicts of Interest: The authors had no conflicts of interest.

Funding/Support: This work was financially supported by grant number 945160 , from the vice-chancellor for research Affairs of Ahvaz Jundishapur University of Medical Sciences.

\section{References}

1. Kontoyiannis DP, Lewis RE. In: Agents of mucormycosis and entomophthoramycosis. 7 ed. Mandell GL, Bennett JE, Dolin R, editors. Churchill livingstone; 2010.

2. Chowdhary A, Agarwal K, Meis JF. Filamentous Fungi in Respiratory Infections. What Lies Beyond Aspergillosis and Mucormycosis?. PLoS Pathog. 2016;12(4):1005491. doi: 10.1371/journal.ppat.1005491. [PubMed: 27124489].

3. Sharma D, Dahal K, Pathak B, Dahal U. Case of early-disseminated Rhizopus microsporus var. microsporus mucormycosis in a renal transplant patient. Int Med Case Rep J. 2016;9:139-43. doi: 10.2147/IMCRJ.S100395. [PubMed: 27354831].

4. Vaezi A, Moazeni M, Rahimi M, Hoog S, Badali H. Mucormycosis in Iran: a systematic review. Mycoses. 2016.

5. Chakrabarti A, Singh R. Mucormycosis in India: unique features. Mycoses. 2014;57 Suppl 3:85-90. doi: 10.1111/myc.12243. [PubMed: 25187095].

6. Epstein JB, Kupferman SB, Zabner R, Rejali A, Hopp ML, Lill M, et al. Early diagnosis and successful management of oral mucormycosis in a hematopoietic stem cell transplant recipient: case report and literature review. Supportive Care Cancer. 2016:1-4.

7. Faraji E, Nakhjavani M, Mashrabi O, Maleki S, Maleki R. A brief review of mucormycosis: Report of five cases. BJMMR. 2016;11(9):1-5.

8. Yari AR, Goudarzi G, Geravandi S, Dobaradaran S, Yousefi F, Idani E, et al. Study of ground-level ozone and its health risk assessment in residents in Ahvaz city, Iran during 2013. Toxin Reviews. 2016;35(3-4):201-6.

9. Park JH, Park SH, Kang EG, Kyung G, An HD, An S. Cutaneous mucormycosis in a patient with diabetes mellitus. Ewha Med J. 2016;39(1):10-3.

10. Petrikkos G, Skiada A, Lortholary O, Roilides E, Walsh TJ, Kontoyiannis DP. Epidemiology and clinical manifestations of mucormycosis. Clin Infect Dis. 2012;54 Suppl 1:S23-34. doi: 10.1093/cid/cir866. [PubMed: 22247442].

11. Miceli MH, Kauffman CA. Treatment options for mucormycosis. Cur Treat Options Infect Dis. 2015;7(3):142-54.

12. Mendez HH, Hidalgo A. Endodontic patient with rhinocerebral mucormycosis. Revista Odontologica Mexicana. 2015;19(2):120-5.

13. Lim MY, Alker AP, Califano S, Trembath DG, Alby K, Gilligan PH, et al. Concurrent Disseminated Nocardiosis and GI Mucormycosis in a Stem-Cell Transplantation Recipient. J Clin Oncol. 2016;34(10):84-6. doi: 10.1200/JCO.2013.51.4042. [PubMed: 25071136].

14. Hong HL, Lee YM, Kim T, Lee JY, Chung YS, Kim MN, et al. Risk factors for mortality in patients with invasive mucormycosis. Infect Chemother 2013;45(3):292-8. doi: 10.3947/ic.2013.45.3.292. [PubMed: 24396630].

15. Neblett Fanfair R, Benedict K, Bos J, Bennett SD, Lo YC, Adebanjo T, et al. Necrotizing cutaneous mucormycosis after a tornado in Joplin, Missouri, in 2011. N Engl J Med. 2012;367(23):2214-25. doi: 10.1056/NEJMoa1204781. [PubMed: 23215557].

16. Roden MM, Zaoutis TE, Buchanan WL, Knudsen TA, Sarkisova TA Schaufele RL, et al. Epidemiology and outcome of zygomycosis: a review of 929 reported cases. Clin Infect Dis. 2005;41(5):634-53. doi: 10.1086/432579. [PubMed: 16080086].

17. Ibrahim AS, Spellberg B, Walsh TJ, Kontoyiannis DP. Pathogenesis of mucormycosis. Clin Infect Dis. 2012;54 Suppl 1:S16-22. doi 10.1093/cid/cir865. [PubMed: 22247441]. 
18. Goudarzi G, Geravandi S, Foruozandeh H, Babaei AA, Alavi N, Niri MV, et al. Cardiovascular and respiratory mortality attributed to groundlevel ozone in Ahvaz, Iran. Environ Monit Assess. 2015;187(8):487. doi: 10.1007/s10661-015-4674-4. [PubMed: 26141926].

19. Salmanzadeh S, Yousefi F, Ahmadi F, Geravandi S, Moien M, Mohammadi M, et al. Evaluation of Nosocomial Infections in a Teaching Hospital. Avicenna J Clin Microbiol Infect. 2015;2(3).

20. Mohinisingh D. Mucormycosis an Emerging Fungal Infection. Indian J app Res. 2015;5(8):661-4.

21. Sachdeva K. Rhino-oculo Cerebral Mucormycosis with Multiple Cranial Nerve Palsy in Diabetic Patient: Review of Six Cases. Indian Otolaryngol Head Neck Surg. 2013;65(4):375-9. doi: 10.1007/s12070-0130659-1. [PubMed: 24427603].

22. Saegeman V, Maertens J, Ectors N, Meersseman W, Lagrou K. Epidemiology of mucormycosis: review of 18 cases in a tertiary care hospital. Med Mycol. 2010;48(2):245-54. doi: 10.1080/13693780903059477. [PubMed: 19568978].

23. Khor B, Lee M, Leu H, Liu J. Rhinocerebral mucormycosis in Taiwan. J microbiol immunol infect. 2003;36(4):266-9.

24. Barati M, Talebi-Taher M, Nojomi M, Kerami F. Ten-year experience of rhinocerebral zygomycosis in a teaching hospital in Tehran. Arch Clin Infect Dis. 2010;5(3):117-20.

25. Bitar D, Van Cauteren D, Lanternier F, Dannaoui E, Che D, Dromer $\mathrm{F}$, et al. Increasing incidence of zygomycosis (mucormycosis),
France, 1997-2006. Emerg Infect Dis. 2009;15(9):1395-401. doi: 10.3201/eid1509.090334. [PubMed: 19788806].

26. Sarvestani AS, Pishdad G, Bolandparvaz S. Predisposing factors for mucormycosis in patients with diabetes mellitus; an experience of 21 years in southern iran. Bulletin Emerg Traum. 2013;1(4):164.

27. Komur S, İnal A, Kurtaran B, Ulu A, Uguz A, Aksu H, et al. Mucormycosis: a 10-year experience at a tertiary care center in Turkey. Turkish J Med Sci. 2016;46(1):58-62.

28. Pagano L, Ricci P, Tonso A, Nosari A, Cudillo L, Montillo M, et al. Mucormycosis in patients with haematological malignancies: a retrospective clinical study of 37 cases. GIMEMA Infection Program (Gruppo Italiano Malattie Ematologiche Maligne dell'Adulto). $\mathrm{Br}$ J Haematol. 1997;99(2):331-6. [PubMed: 9375750].

29. Bartzokas CA. Relationship between the metereological conditions and the air-borne fungal flora of the Athens metropolitan area. Mycopathologia. 1975;57(1):35-8. [PubMed:1207718].

30. El-Herte RI, Baban TA, Kanj SS. Mucormycosis: a review on environmental fungal spores and seasonal variation of human disease. Adv Infect Dis. 2012;2(03):76.

31. Chakrabarti A, Das A, Mandal J, Shivaprakash MR, George VK, Tarai $\mathrm{B}$, et al. The rising trend of invasive zygomycosis in patients with uncontrolled diabetes mellitus. Med Mycol. 2006;44(4):335-42. doi: 10.1080/13693780500464930. [PubMed: 16772227]. 